\title{
Alfabetização científica e iniciação científica: da assimilação de conceitos ao comportamento científico
}

\section{Scientific literacy and scientific initiation: the assimilation of concepts into scientific behavior}

\section{Alfabetización científica e iniciación científica: de la asimilación de conceptos al comportamiento científico}

http://dx.doi.org/10.221713/2358-2332.2016.v14.1472 ${ }^{1}$

Rosemary Conceição dos Santos, doutora em Letras Clássicas e Vernáculas pela Universidade de São Paulo (USP), pesquisadora em Cultura, Memória e Política da Faculdade de Filosofia, Letras e Ciências Humanas da USP e bolsista de Divulgação Científico-Cultural da Casa da Ciência da Fundação Hemocentro de Ribeirão Preto (Fundherp), Ribeirão Preto, SP, Brasil. E-mail: cienciausp@usp.br.

Marisa Ramos Barbieri, doutora em Filosofia pela Universidade de São Paulo (USP), professora colaboradora da Faculdade de Filosofia, Ciências e Letras de Ribeirão Preto da USP e coordenadora da Casa da Ciência da Fundação Hemocentro de Ribeirão Preto (Fundherp), Ribeirão Preto, SP, Brasil. E-mail: marisarbarbieri@ gmail.com.

Roberto Galetti Sanchez, graduado em Ciências Biológicas pelo Centro Universitário Barão de Mauá de Ribeirão Preto, bolsista da Fundação Hemocentro de Ribeirão Preto (Fundherp), Ribeirão Preto, SP, Brasil. E-mail: casadaciencia@ hemocentro.fmrp.usp.br.

\section{Resumo}

Este trabalho trata da promoção de alfabetização e iniciação científicas em alunos da rede básica de ensino, desenvolvidas por pós-graduandos de programas stricto sensu atuantes, desde 2012, na Casa da Ciência (Hemocentro de Ribeirão Preto), projeto integrante do Instituto Nacional de Ciência e Tecnologia (INCT) em Células-Tronco e Terapia Celular no Câncer. Em dez encontros, após a apresentação de conteúdos científicos aos alunos, e esclarecimento dialogado de eventuais dúvidas, verifica-se, através de pesquisa qualitativa, a capacidade destes em identificar, e analisar, os temas apresentados. Em casos pontuais, o projeto ressalta peculiaridades docentes e discentes evidenciadas durante sua vigência, a saber: antecipar a prática de ensinar com ciência e tecnologia junto a futuros profissionais da educação superior e aprimorar as habilidades cognitivas refletidas no desempenho escolar discente, respectivamente.

\footnotetext{
${ }^{1}$ Como citar: ABNT NBR 6023:2002 e incluir o DOI.
} 
Santos, Barbieri e Sanchez / Alfabetização científica e iniciação científica: da assimilação de conceitos ao comportamento científico

Palavras-chave: Alfabetização Científica. Iniciação Científica. Assimilação de Conceitos. Comportamento Científico. Adolescentes. Casa da Ciência.

\begin{abstract}
This paper deals with the promotion of literacy and scientific initiation among students from the basic education network, as the responsibility of students of graduate programs, since 2012, in the House of Science (Hemocentro de Ribeirão Preto), an integral project of the National Science Institute and Technology (INCT) in Stem Cells and Cancer Cell Therapy in Cancer. In ten meetings, after the presentation of scientific content to the students, and a dialogical clarification of any doubts, it is verified, through qualitative research, the ability of these students to identify and to analyze the presented themes. In specific cases, the project emphasizes teaching and learning peculiarities evidenced during its validity, namely: anticipating the practice of teaching with science and technology with future professionals of higher education and improving the cognitive abilities reflected in the student's academic performance, respectively.
\end{abstract}

Keywords: Scientific Literacy. Scientific research. Assimilation of Concepts. Scientific Behavior. Adolescents. House of Science.

\title{
Resumen
}

Este trabajo trata de la promoción de la alfabetización y la iniciación científica entre los estudiantes de la red de educación básica, bajo la responsabilidad de los estudiantes de postgrado de los programas stricto sensu, desde 2012, en la Casa de la Ciencia (Hemocentro de Ribeirão Preto), un proyecto integral del Instituto Nacional de Ciencia y Tecnología (INCT) en células madre y terapia celular adoptiva (o terapia celular contra el cáncer). En diez encuentros, después de la presentación de contenidos científicos a los alumnos, y aclaración dialogada de eventuales dudas, se verificó, através de investigación cualitativa, la capacidad de estos contenidos en identificar y analizar los temas presentados. En casos puntuales, el proyecto resalta peculiaridades docentes y discentes evidenciadas durante su vigencia, a saber: anticipar la práctica de enseñanza con ciencia y tecnología junto a futuros profesionales de la educación superior y perfeccionar las habilidades cognitivas reflejadas en el desempeño escolar.

Palabras clave: Alfabetización Científica. Iniciación Científica. Asimilación de conceptos. Comportamiento Científico. Adolescentes. Casa de la Ciencia.

\section{INTRODUÇÃO}

Desempenhando papel fundamental na expansão e consolidação da pós-graduação stricto sensu (mestrado e doutorado) em todos os estados da Federação, a Coordenação de Aperfeiçoamento de Pessoal de Nível Superior (Capes) também atua, desde 2007, na formação de professores da educação básica, ampliando o alcance de suas ações na formação de pessoal qualificado no Brasil e no exterior. Em 2009, a homologação da Lei 
Santos, Barbieri e Sanchez / Alfabetização científica e iniciação científica: da assimilação de conceitos ao comportamento científico

n 11.502/2007 (BRASIL, 2007) cria a "Nova Capes" que, além de coordenar o alto padrão do Sistema Nacional de Pós-Graduação brasileiro, passa a induzir, e fomentar, a formação inicial e continuada de professores para a educação básica. Tal atribuição é consolidada pelo Decreto ${ }^{\circ} 6.755$ (BRASIL, 2009), de 29 de janeiro de 2009, que instituiu a Política Nacional de Formação de Profissionais do Magistério da Educação Básica. Reestruturada, a Capes passa a desenvolver diversas ações de acordo com a sua nova missão: implementando uma série de programas que visam contribuir para o aprimoramento da qualidade da educação básica e para a estimulação de experiências inovadoras por meio do uso de recursos e tecnologias de comunicação e informação nas modalidades de educação presencial e a distância.

Em 2014, o Ministério da Ciência, Tecnologia e Inovação (MCTI), em parceria com a Capes, com o Conselho Nacional de Desenvolvimento Científico e Tecnológico (CNPq), com a Fundação de Amparo à Pesquisa do Estado de São Paulo (Fapesp) e demais Fundações Estaduais de Amparo à Pesquisa (FAP), anunciou a Chamada INCT MCTI/CNPq/Capes/FAPs (CONSELHO NACIONAL DE DESENVOLVIMENTO CIENTÍFICO E TECNOLÓGICO, 2014), voltada ao recebimento de propostas de pesquisa interessadas na implementação de Institutos Nacionais de Ciência e Tecnologia (INCT). Nesse contexto, a Fundação Hemocentro de Ribeirão Preto (Fundherp), uma das instituições escolhidas pelo MCTI para sediar o INCT em Células-Tronco e Terapia Celular no Câncer, em cumprimento à sua missão - de pesquisa, formação de recursos humanos, transferência de conhecimentos para a sociedade, transferência de conhecimento para o setor empresarial e para o setor público, e internacionalização - , instituiu o projeto Casa da Ciência, fundamentado na promoção de alfabetização e iniciação científicas de alunos da rede básica de ensino, mediante atividades desenvolvidas por pós-graduandos de diversos programas de pós-graduação strictosensu, públicos e privados, desde 2012.

Este trabalho, apresentando a definição dos conceitos alfabetização e iniciação científicas, trata dessa promoção, ressaltando, em dois casos pontuais da Casa da Ciência do Hemocentro de Ribeirão Preto, a multidisciplinaridade voltada à formação de qualificados recursos humanos no país, bem como as peculiaridades de um trabalho docente que antecipa a prática de ensinar e orientar com ciência e tecnologia junto a esses futuros profissionais da educação superior. Ao final, traz considerações sobre o dialogismo dos conhecimentos adquiridos na formação universitária com os saberes necessários que a educação básica reclama para a resolução de conflitos formativos no cotidiano escolar.

\section{ALFABETIZAR: ENSINAR PARA INTEGRAR}

Etimologicamente, alfabetização é o ato de ensinar as primeiras letras a alguém, iniciando-o na aquisição dos códigos alfabético e numérico para uso do sistema ortográfico (HOUAISS, 2001, p. 150). Em As muitas facetas da alfabetização, Magda Soares (1985) diferencia o processo de aquisição da língua do processo de desenvolvimento da mesma, apresentando três perspectivas para estudo da alfabetização, 
Santos, Barbieri e Sanchez / Alfabetização científica e iniciação científica: da assimilação de conceitos ao comportamento científico

a saber: a "conceitual", a de "natureza do processo" e a perspectiva dos seus "condicionantes".

A perspectiva conceitual prioriza o significado de a alfabetização levar à aquisição do alfabeto, sem ultrapassar os limites da especificidade, ou seja, de "ensinar o código da língua escrita, ensinar as habilidades de ler e escrever" (SOARES, 1985, p. 20). Afirmação esta que nos requisita esclarecer que o debate básico de ler e escrever envolve dois amplos pontos de vista: 1) o da mecânica da língua (LEMLE, 1984, p. 41), representando fonemas (sons) em grafemas (letras) - processo de escrita - e grafemas em fonemas - processo de leitura -, construindo uma relação adequada entre sons e letras da língua portuguesa; e 2) o da apreensão e compreensão de significados (KRAMER, 1982, p. 62), representando um objeto por meio de substituições gradativas, visando à comunicação, à aquisição de conhecimento e à troca de sentidos.

Por essa perspectiva, admite-se a conclusão parcial de que alfabetização é um processo que envolve a ocorrência de ambos os pontos de vista citados, e não encerra em ambos, haja vista que não é considerado alfabetizado quem, apenas, decodifica códigos visuais em sonoros, e vice-versa. O mesmo podendo ser dito de quem se limita a ler sílabas e palavras isoladas, incapaz de usar o sistema ortográfico para se expressar por escrito. Em busca de uma conclusão integral, complementam-se tais aspectos individuais da alfabetização com aspectos sociais, dependentes de características culturais, econômicas e tecnológicas que se destacam por serem diferentes processos de alfabetização, dependentes de onde ocorrem nos quatro quadrantes do mundo, caso específico do que se convencionou chamar de alfabetização funcional.

No que se refere à natureza do processo, a alfabetização é compreendida não como uma única habilidade, mas, sim, como o conjunto destas, cuja natureza complexa e multifacetada justificam o porquê da diversidade de áreas, como é o caso da Psicologia, da Psicolinguística, da Sociolinguística e da Linguística, que se interessam em estudá-la, compreendê-la e explicá-la, ainda que fragmentariamente. Tradicionalmente, reside na Psicologia (DA SILVA, 2003) o interesse em estudar a associação da alfabetização aos testes de QI (Quociente Intelectual), bem como a associação da alfabetização aos aspectos neurológicos, fisiológicos e psicológicos do indivíduo, também mensurados por testes psicológicos, considerados na área enquanto medidas das condições intelectuais, fisiológicas e neurológicas da criança para tal. No primeiro caso, a associação se dá atribuindo à ideologia do dom o sucesso e o fracasso do indivíduo na aprendizagem da leitura e de escrita, entendendo estas como dependentes do QI e de aptidões específicas. No segundo caso, isso ocorre mediante a percepção do esquema corporal, e estruturação espacial e temporal, das disfunções psiconeurológicas da aprendizagem da leitura e escrita, conhecidas como afasia, dislexia, disgrafia, disortografia, disfunção cerebral mínima etc.

Com a teoria piagetiana dos processos de aquisição de conhecimento (PIAGET, 1975a; 1975b; 1996; 1999; PIAGET, INHELDER, 1982), o foco dos estudos sobre alfabetização se volta para as abordagens cognitivas nas quais o sucesso, ou fracasso, da alfabetização se relaciona, relembrando Emília Ferreiro (1985), por exemplo, com o estágio de compreensão da natureza simbólica da escrita em que se encontra a criança. 
Santos, Barbieri e Sanchez / Alfabetização científica e iniciação científica: da assimilação de conceitos ao comportamento científico

Por sua vez, na área de Psicolinguística, o interesse, segundo Kato (1984), voltase para a caracterização da maturidade linguística da criança em aprender a ler e a escrever, em estabelecer relações entre linguagem e memória e entre linguagem visual e linguagem não visual, chegando na determinação da quantidade de informação apreendida pelo campo visual durante a leitura, entre outros. Na Sociolinguística, a alfabetização, segundo Labov (2008), é vista como um processo relacionado aos usos sociais da língua, nos quais pesam as diferenças dialetais já dominadas pela criança mais próximas ou mais distantes - da norma padrão do idioma, usadas em situações formais, e da norma padrão cultural do idioma - diferente em cada região do país adicionada a diferentes oportunidades de contato com materiais escritos. Na Linguística, de acordo com Silva (1981), a alfabetização é vista como um processo de transferência da forma sonora da fala para a forma gráfica da escrita, onde a criança passa a estabelecer relações entre sons e símbolos gráficos e entre fonemas e grafemas, reconhecendo quando um mesmo fonema pode ser representado por mais de um grafema e, com isso, adquirindo um progressivo domínio das regularidades e irregularidades do idioma.

$\mathrm{Na}$ perspectiva dos condicionantes do processo de alfabetização, que regulam a aprendizagem da leitura e escrita na escola, temos que, enquanto aspecto social, as práticas linguísticas oral e escrita de crianças de baixa-renda são rejeitadas em ambientes de valorização da norma culta escrita e falada, os quais atribuem às primeiras a rotulação de carregarem um deficit cultural e linguístico, conceitos estes insustentáveis científica e ideologicamente uma vez que língua e cultura são elementos diferentes um do outro, mas não melhores nem piores entre si. Por adição, enquanto aspecto político, a alfabetização, entendida como forma de pensamento, de construção do saber e conquista de poder político consciente, é o que pode aproximar as classes desfavorecidas à construção e partilha do saber, uma vez que, desalienadas do contexto em que vivem, passam a conhecer seus direitos e deveres, lutando por eles. Logo, a diferença entre métodos de alfabetização decorre da priorização de um desses condicionantes em relação ao outro e requer uma articulação efetiva entre os métodos psicológico, psicolinguístico, sociolinguístico e linguístico, por ocasião do ensino de leitura e escrita.

Nesse contexto, uma vez alfabetizada, a criança, para especializar seu conhecimento, ou seja, para conhecer mais pormenorizadamente um determinado tema, passa a necessitar de domínio de pré-requisitos, aqui entendidos como conceitos, os quais viabilizarão sua assimilação do conhecimento novo que estes engendram. Maluf (1987), ao tratar da definição de "conceito", no processo de alfabetização, o esclarece como a expressão do pensamento, ideia ou noção que coloca a criança no ambiente do abstrato, alcançável, este, pela generalização de observações particulares. Alguns exemplos: a palavra "tamanho" é um conceito que expressa se um determinado objeto, em comparação com outro, tomado como referencial, é maior ou menor, bem como muito maior ou muito menor, aproximando os alunos do que vem a ser o conceito de "escala". Do mesmo modo, a palavra "leitura" é um conceito que expressa uma série de interações do ser com as particularidades de um sistema de códigos escritos. Com isso, tem-se que os conceitos, que concedem noção de elementos, são expressões de determinada extensão que, por 
Santos, Barbieri e Sanchez / Alfabetização científica e iniciação científica: da assimilação de conceitos ao comportamento científico

meio de suas características gerais, remetem a particularidades e características que permitem sua delimitação.

Considerando, entretanto, que a comunicação e o registro do conhecimento são imprescindíveis para a constituição de um campo de saber (ALMEIDA, 1994; CABRÉ, 2003), a alfabetização, tal como é definida por Soares (1985), deve estar presente nos mais variados contextos - científico, artístico, econômico, literário, político, filosófico etc. -, ocasiões estas em que oportuniza uma escolha conceitual adequada, promotora de esclarecidas situações comunicativas. Em outras palavras, muito mais do que decodificar símbolos - ainda que imprescindível - a alfabetização deve propiciar a leitura, e interpretação do mundo. Nas palavras de Chassot (2003, p. 91), sendo a ciência uma linguagem, "[...] ser alfabetizado cientificamente é saber ler a linguagem em que está escrita a natureza". Definição esta que, por similitude, nos permite afirmar que, ser alfabetizado artisticamente, economicamente, literariamente, politicamente e filosoficamente, entre outros, é saber ler a linguagem em que está escrita a arte, a economia, a literatura, a política e a filosofia, respectivamente. Neste contexto, Maciel (2010 ) conclui que o desenvolvimento de linguagens específicas é uma decorrência natural da especialização da atividade humana, e consequente formação de grupos de trabalho que as utilizam, ao que De Meis (1998), em sua precursora tentativa de aproximar, por intermédio de cursos experimentais envolvendo professores e estudantes do ensino fundamental e médio, quem "faz" ciência de quem "ensina" ciência, acresce se tratarem, estes, de momentos efetivos de construção de fatos e de descobertas autênticas das ciências biológicas.

\section{ALFABETIZAÇÃO CIENTÍFICA: INTEGRAR PARA CONHECER}

Para Kerlinger (1973, p. 30), entender ciência, ou pesquisa científica, como forma de gerar conhecimento útil de modo sistemático e controlado é ato que orienta o termo "conceituar" a assumir duas representações imprescindíveis: a de "significação constitutiva" e a de "significação operacional". Na primeira, está a definição de uma palavra usando outras palavras (substituição de um conceito por outro); na segunda, está a definição dessa mesma palavra mediante ações e comportamentos que ela expressa ou implica (interação de um conceito com o real observado). A constitutiva permite estabelecer conexões entre as palavras utilizadas e os dados observados. A operacional permite ao pesquisador medir e manipular variáveis na realidade empírica. Interessam a este trabalho tanto as significações constitutivas quanto as significações operacionais alcançadas pelos alunos nos casos específicos que serão apresentados ao longo do texto.

Por sua vez, o uso inicial da expressão "alfabetização científica" (scientific literacy) se localiza nos anos 1950, em território americano (DEBOER, 2000; HURD, 1998), por ocasião de um relatório produzido nos Estados Unidos (ROCKEFELLER BROTHERS FUND, 1958, p. 369), no qual se indicava que "[...] toda pessoa educada deve ser alfabetizada/letrada em ciências", caso o sistema educacional de seu país pretenda prepará-las de modo mais eficiente para viver e trabalhar num mundo movido a mudanças rápidas. Ainda que o referido documento não defina o conceito, deixa 
Santos, Barbieri e Sanchez / Alfabetização científica e iniciação científica: da assimilação de conceitos ao comportamento científico

subentendido que "educação científica" é produto da alfabetização escolar, na qual a criança entra em contato com a herança de conhecimentos que lhe foi deixada pela humanidade, tornando-se capaz de entender o mundo natural e de ficar mais informada, o que a capacitaria para alcançar uma experiência mais inteligente do cotidiano (DEBOER, 2000, p. 592).

Em Marcuschi (2007, p. 23), assim como nos planos desenvolvimentistas da Unesco que associam "analfabetismo" a atraso geral, pobreza e doença e "alfabetismo" a progresso, saúde e bem-estar econômico, entendemos que a "alfabetização científica", à semelhança da apropriação desejável da escrita e leitura para que uma sociedade desempenhe bem e progrida, pode ser utilizada de forma mais eficaz no preparo das crianças visando a um melhor enfrentamento da vida e do trabalho, num mundo cada vez mais modificado pela tecnologia. Considerando os aspectos positivos e negativos que envolvem o termo, Deboer (2000) concorda que scientific literacy represente um objetivo educacional relevante, mas discorda da ideia de que o termo represente "uma ferramenta cultural fundamental comparada à leitura, à escrita e à aritmética" (DEBOER, 2000, p.595). Outros autores, por sua vez, entendem a alfabetização científica como um aprendizado de atividades de investigação científica que, levantando questões e expondo dúvidas, promove, na criança, a consciência do que seja estabelecer propósitos, desenvolver hipóteses e inferir resultados (MARTINS, 2008).

Miller (1983), entendendo alfabetização científica como a capacidade de ler, escrever e compreender conceitos científicos, acrescenta na sua definição do conceito a qualidade de promover consciência do impacto que a ciência, juntamente com a tecnologia, causam na sociedade. Definição esta complementada por Arruda (2002, p. 130), que, baseando-se na Teoria das Representações Sociais (TRS), parte da premissa de que existem formas diferentes de conhecer e de se comunicar guiadas por objetivos diferentes, que são as formas consensual e científica, diferenciadas apenas por focarem objetivos diversos e não por hierarquia, tampouco, por isolamento. A forma consensual se baseia no senso comum e na consciência coletiva, identificando o social como um grupo de indivíduos iguais, com a mesma competência, compreendida como etnociência. A científica busca retratar a realidade, independente da consciência coletiva, identificando o social como um sistema em que os indivíduos assumem papéis e classes diferentes, no qual cabe aos especialistas, por argumento de autoridade, o direito à palavra final sobre determinados conhecimentos.

No contexto da alfabetização científica, o conhecimento consensual pode ser retratado pelas noções e informações que os alunos trazem de casa e dos ambientes que frequentam, enquanto o conhecimento científico é retratado pela especificação de termos a serem utilizados para se referirem a determinado elemento, ou assunto, próprio do ambiente acadêmico que passam a frequentar. Cumpre, então, indagarmos: se a construção de conhecimentos ocorre em saberes distintos, tais como em ciência, em história, em tecnologia, em artes, em direito, em política, em economia, em literatura, em física, entre outros, podemos afirmar que existem diferentes formas de alfabetização científica? Afirmando que sim, Shen (1975) propõe três formas, distintas entre si, não só em seus objetivos, mas também em sua audiência, conteúdo, formato e meios de 
Santos, Barbieri e Sanchez / Alfabetização científica e iniciação científica: da assimilação de conceitos ao comportamento científico

divulgação. São elas: "alfabetização científica prática" (pratical science literacy), "alfabetização científica cívica" (civic science literacy) e "alfabetização científica cultural" (cultural science literacy).

Prática, é o conhecimento científico e técnico básico sobre alimentação (nutrição e agricultura moderna), saúde (contaminação) e abrigo (locais seguros) que, podendo ser imediatamente utilizados para melhorar o padrão de vida, podem aliviar a desinformação tanto de cerca de um bilhão de pessoas que vivem em pobreza profunda, mesmo que isso não consiga corrigir as desigualdades socioeconômicas que estão na raiz de tais dificuldades, quanto de pessoas que vivem em países desenvolvidos e necessitam de informações pontuais para respaldarem suas escolhas. Exemplos: desde saber que a amamentação é a forma mais segura e eficaz para bebês, a saber fazer bom uso de sementes na hora plantio, respectivamente. A julgar pelo elevado número de pessoas que necessitam de tal tipo de alfabetização no mundo, trata-se de tarefa complexa que reclama esforço concentrado em meios de comunicação de massa.

Cívica, é o conhecimento consciente do cidadão sobre a relação existente entre a ciência e as questões sociais, o qual he possibilita verificar se seus representantes políticos estão cientes do mesmo antes de tomarem decisões que afetem toda a sociedade. Neste contexto, é primordial separar ciência de achismos, única forma de discernir riscos e benefícios. Como alcançar isso? Expondo o público à divulgação científica de qualidade, em linguagem clara e em quantidade que lhe permita a familiarização e a conscientização de suas implicações sociais.

Cultural, é conhecimento prazeroso das realizações científicas alcançadas por ilustres cientistas em suas respectivas áreas. Permite, através de narrativas presentes em artigos, livros, programas de televisão, cinema, palestras, filmes, quadrinhos e jogos, formas lúdicas de apreensão da ciência e suas subjetividades, tal como é possível desfrutar das letras, da música e das artes plásticas. Cumpre, também, e muito bem, o papel de exorcizar muitas crenças pseudocientíficas movidas por crenças supersticiosas e ocultas, fomentadoras de irracionalidades, que encontram solo fértil em jovens em formação. Um exemplo é o recente e irracional jogo de mutilações que viralizou nas redes sociais, levando incontável número de jovens à morte. Nessa direção, o amadurecimento da consciência, por parte do aluno, se revela estratégia educacional que se soma à adesão deste a trabalhos colaborativos (capacidade de produzir em equipe), interdisciplinares (habilidade de estabelecer conexões entre diversas áreas do saber), comportamentos de empatia aplicada (tolerância, compaixão, colocar-se na posição do outro, agindo em função disso), e a estímulos à visão empreendedora (domínio de linguagens e de plataformas digitais, desenvolvidos, em conjunto, pela alfabetização científica), fundamentais ao exercício de discernimento da criança.

Logo, a alfabetização científica, quando voltada à otimização do conhecimento produzido pela ciência, prioriza a assimilação de conceitos científicos; voltada à formação cidadã, prioriza o desenvolvimento de atitudes e valores (RATCLIFFE; GRACE, 2003). Identifica-se aqui, portanto, do ponto de vista metodológico, uma das mais importantes perspectivas da alfabetização científica para os próximos anos, senão da própria educação, a saber: uma mudança progressiva de foco em direção a privilegiar as 
Santos, Barbieri e Sanchez / Alfabetização científica e iniciação científica: da assimilação de conceitos ao comportamento científico

chamadas competências metacognitivas (aprendizagem independente), incluindo as habilidades interdisciplinares (solução de problemas complexos), transversais (cumprimento simultâneo de multitarefas em equipe) e emocionais (perseverança e autocontrole emocional).

Na contemporaneidade, a alfabetização científica, possibilitando exploração e compreensão dos meios natural e social, à luz de conteúdos advindos de informações teóricas, vivências e métodos de ensino, sobressai ao habilitar-se a dar respostas para temas que continuam sem respostas, como, por exemplo, a capacidade de entender bem textos complexos. Como? Explorando a metacognição bem além dos procedimentos usuais de transmissão simples do conhecimento, privilegia a orientação precisa e eficiente do conteúdo disponibilizado, adotando abordagens emancipadoras, especialmente aquelas baseadas no processo maiêutico e em aprendizagem independente.

Do latim scientia, e significando "conhecimento", a ciência é produzida principalmente pela pesquisa científica. Inédita ou não, constitui-se, por princípio, de toda produção relevante para o mundo científico, ou, relembrando Umberto Eco (1988, p. 22), "[...] deve dizer do objeto algo que ainda não foi dito ou rever, sob uma óptica diferente, o que já se disse". Característica esta que a leva a congregar as quatro premissas básicas a seguir: o conhecimento (verdadeiro e/ou empírico), a sistematização (organização), a experimentação (verificação) e a demonstração (reprodução). Em outras palavras, o conhecimento científico é o saber tanto de algo verdadeiro quanto de algo empírico; organizado e ordenado metodicamente; fruto de experimentação que permite sua verificação e testagem até ser confirmado; e, uma vez corroborado, é demonstrável, podendo ser reproduzido e sustentado por outros pesquisadores.

Não exclusiva da pós-graduação, enquanto atividade de pesquisa que introduz o aluno na prática científica, a Iniciação Científica pode ser entendida como um processo de aquisição de um comportamento focado na aplicação dos conceitos adquiridos com a alfabetização científica. Nesse contexto, ao submeter o aluno a um planejamento e organização diferenciados, com previsão de erros e sistematização de execução, é a atividade que leva os alunos a aprimorarem seu desempenho acadêmico-científico, o que se reflete no desenvolvimento individual de cada um.

Acrescenta-se que o contato com diferentes áreas do conhecimento - ao promover o relacionamento dos alunos com profissionais de várias especialidades - favorece a multidisciplinaridade, formando recursos humanos qualificados a desenvolverem capacidades diferenciadas em expressões oral e escrita e em habilidades manuais. Ademais, inicia o estudante à apreensão crítica de conteúdos, orientando-o a decidir, comparativamente e com fundamento, entre escolher $\mathrm{A}$ ao invés de $\mathrm{B}$, atitude indispensável não só ao aprendizado como por toda a vida. Habilitando-o a interpretar fatos e a discernir se pode resolvê-los ou se necessita de alguém mais experiente para tal, a Iniciação Científica permitirá ao aluno exercer qualquer tipo de profissão com melhor capacidade de análise crítica, maturidade intelectual e condições para o enfrentamento de dificuldades. Cumpre acrescentar, tal processo também viabiliza a identificação dos melhores talentos dentre seus alunos, os quais, em face do convívio com pesquisadores 
Santos, Barbieri e Sanchez / Alfabetização científica e iniciação científica: da assimilação de conceitos ao comportamento científico

muito experientes, "queimam etapas", desempenhando com mais criatividade e sensatez em seu cotidiano.

Tomando por base alguns resultados obtidos por grupos de pesquisa do Pequeno Cientista, atividade educacional da Casa da Ciência do Hemocentro de Ribeirão Preto, projeto integrante do Instituto Nacional de Ciência e Tecnologia (INCT) em CélulasTronco e Terapia Celular no Câncer, que busca complementar a formação de orientandos e orientadores no ensino de ciência e tecnologia, procuramos evidenciar, neste trabalho, aprendizados decorrentes da promoção da alfabetização científica. Iniciando-se durante as primeiras fases da formação educacional, quando ocorre a assimilação de conceitos científicos pelas crianças, tais aprendizados são posteriormente aplicados no exercício que estas fazem das linguagens oral e escrita, integrando-se ao que elas leem em seu cotidiano, o que concretiza a inter-relação do conteúdo científico com outros temas.

\section{ALFABETIZANDO E INICIANDO CIENTIFICAMENTE}

Proposto em 2010 e implementado em 2012 na Casa da Ciência do Hemocentro de Ribeirão Preto, o Pequeno Cientista propõe aproximar o aluno da rede básica de ensino de atividades de pesquisa científica que os estimulem a observar eventos, formular hipóteses e propor formas de testá-las, confirmando-as ou não. Nesse caminho, os alunos são iniciados por um orientador, ou grupo de orientadores, em sua maioria pósgraduandos de programas de pós-graduação stricto sensu, públicos e privados, que busca $(m)$ ensiná-los a desenvolver uma investigação baseada no método científico, por meio da articulação de conceitos básicos, medianos e complexos e de suas aplicações em variadas situações. Logo, tanto o aluno é alfabetizado cientificamente quanto seu(s) orientador(es) são iniciados em atividades de orientação discente, as quais lhe serão cobradas num futuro próximo de suas carreiras científico-acadêmicas. Trata-se, portanto, de um ambiente de incentivos alinhados, tanto para alunos, quanto para pesquisadores e suas universidades, que o programa, valendo-se da estrutura pré-existente, coloca em prática.

Uma vez apresentados aos orientadores, que lhes expõem os temas com os quais irão trabalhar, os alunos são convidados a formarem grupos, escolhendo a temática com a qual tenham mais afinidade. Também, nessa ocasião, são entregues aos alunos um Caderno da Casa, equivalente ao Caderno de Campo de pesquisadores, no qual os conceitos, as reflexões, as proposições e outras afirmações afins são registradas por eles. Seguem-se, então, oito encontros semanais, nos quais a temática é desenvolvida. Esperase que, no $9^{\circ}$ encontro, o grupo de alunos se encontre apto a preparar um pré-mural, pôster inicial, que contemple os conceitos, atividades e resultados aprendidos e receba as devidas correções e intervenções dos orientadores, quando necessário. No $10^{\circ}$ encontro, o mural definitivo deve ser apresentado ao(s) orientador(es) e demais grupos. Finalizando o projeto daquele semestre, um evento de encerramento, nos moldes de um congresso científico, é organizado pelos grupos e, com a apresentação dos murais definitivos, as atividades são concluídas. 
Santos, Barbieri e Sanchez / Alfabetização científica e iniciação científica: da assimilação de conceitos ao comportamento científico

Preocupando-se, portanto, com aspectos da realidade que não podem ser quantificados, mas, sim, centrados na compreensão e explicação da dinâmica das relações sociais (MINAYO, 2001), apresentamos, a seguir, dois casos da pesquisa qualitativa, a fim de que se conheça como seus projetos foram conduzidos no contexto do programa. $\mathrm{Na}$ sequência, os alcances e limitações que evidenciaram são especificados e as habilidades apresentadas pelos docentes e discentes são discutidas.

\subsection{Caso 1: explorando o Sistema Nervoso}

Em dez encontros, ocorridos no Hemocentro de Ribeirão Preto, o orientador, docente da Faculdade de Medicina de Ribeirão Preto da Universidade de São Paulo (FMRP-USP), em colaboração com uma mestranda em Neurociências e Comportamento da mesma instituição, apresentaram a um grupo de 11 alunos o funcionamento do Sistema Nervoso Humano. Inicialmente, buscaram responder a duas questões básicas: "O que é o Sistema Nervoso?" e "Para que serve?". Apresentados os slides da anatomia do Sistema Nervoso, os alunos, atentos e curiosos, quiseram saber quais eram as suas células. Nos encontros seguintes, modelos anatômicos de plástico, representando as diversas estruturas do Sistema Nervoso, foram montados e desmontados pelos alunos, com vivaz alegria. Discutiu-se como a "forma" estava associada a "função", bem como o que eram as meninges, a medula espinhal, o tronco encefálico, o encéfalo e o Líquido Cefalorraquidiano (LCR). Os alunos quiseram saber "Qual a função de tantos giros, e sulcos, no cérebro e cerebelo?" e "Quais as funções, e importância, do líquor?". Na sequência, trabalhando-se as diferenças das células neurônio e glia, e as principais estruturas do neurônio e suas propriedades fundamentais (excitabilidade; condutibilidade e transmissão sináptica), os orientadores manifestaram ser o tempo sempre curto para administrar tamanho interesse, realçando a disciplina dos alunos em registrar os conceitos e informações em seus respectivos cadernos de aula e seu interesse ao solicitarem a outro aluno que esclarecesse eventuais dúvidas que surgissem. Apresentados os conceitos de "potencial de ação" - seguido de uma dinâmica de grupo, na qual cada aluno representava um neurônio capaz de "gerar" eletricidade e conduzi-la pelo axônio até o terminal sináptico - e de "transdução" e "circuitos neurais" - com os alunos "provocados" pelos orientadores a descreverem um Sistema Nervoso Central, que precisaria transformar diferentes formas de energia - mecânica, térmica, química e luminosa - em potencial de ação -, a importância da formação de circuitos neurais para a obtenção de uma resposta comportamental específica foi discutida. Como exemplo mecânico, os orientadores apresentaram o reflexo patelar, que, através do Sistema Nervoso, provoca uma "resposta" ou "comportamento" de extensão de um músculo e contração de outro. Abordando a "função neuromuscular", foi enfatizado que os neurônios também se comunicam pelas fibras musculares (esqueléticas, lisas e cardíacas) e pelas glândulas, o que foi seguido de uma teatralização, na qual os alunos representavam as diferentes proteínas contráteis. Identificada a memória como atividade neural iniciada dentro do Sistema Nervoso, sem a presença do fenômeno da transdução, os alunos exemplificaram, através de suas experiências pessoais, diferentes tipos de memórias. Tratou-se, então, dos experimentos 
Santos, Barbieri e Sanchez / Alfabetização científica e iniciação científica: da assimilação de conceitos ao comportamento científico

históricos acerca da memória (Pavlov, Thorndike, Lashley e Hebb), seguido das preparações do pré-mural e mural.

\subsection{Caso 2: aspectos macroscópicos e microscópicos das doenças hepáticas}

Três pesquisadores, pós-graduandos, orientaram um grupo de cinco alunos sobre o tema "Aspectos macroscópicos e microscópicos das doenças hepáticas". Iniciando o programa, a definição de vesícula biliar, seu funcionamento e a constituição do sistema digestivo foram apresentados, seguidos de explicações sobre o que era uma análise macroscópica (anatômica) do fígado normal, diferenciando-a de uma análise microscópica, e a identificação dos tipos celulares do fígado normal. Na sequência, um vídeo com animação sobre hepatite, tropismo, diapedese e autoimunização foi apresentado. Nos encontros seguintes, o enfoque sobre gastrite e bronquite, citando seus aspectos (sinais flogísticos), como dor, inchaço (edema), vermelhidão e morte celular, caracterizou as formas de inflamação. Os alunos, solicitados então a identificar células inflamatórias ao microscópio, classificaram os órgãos que estavam sendo observados em relação à cronicidade da doença (do mais agudo para o mais crônico), identificando as rugas no fígado e os espaços em branco (capilares dilatados) e sua função. A partir da caracterização teórico-prática desses aspectos, os orientadores associaram tal percurso às etapas do método científico (introdução, hipótese, metodologia e resultados) como uma história a ser contada. Concretizando-a, os alunos traçaram uma linha do tempo, demonstrando as fases e os acontecimentos que identificam as doenças hepáticas.

\section{ALCANCES E LIMITAÇÕES}

Apresentados os casos acima, aferir os resultados que cada projeto conseguiu atingir e as restrições neles evidenciadas é ato fundamental para identificar a qualidade do programa. Dyer (1965), adepto a processos de medida que, para além dos relevantes e indispensáveis escores numéricos, também consideram: a) o conjunto de situações relativas à aprendizagem ocorrida através do ensino; b) as respostas dos indivíduos às situações apresentadas; e c) a classificação dos mesmos indivíduos segundo suas respostas; orienta-nos a analisar os dois casos anteriormente apresentados, refletindo sobre sua "forma" (participações espontâneas ou induzidas dos alunos), "apresentação" (conceitos assimilados) e "comportamento" alcançado (comportamento científico manifestado).

No "Caso 1: explorando o Sistema Nervoso", os orientadores relataram maior dificuldade dos alunos em compreender os conceitos "excitabilidade" e "condutibilidade", dificuldade esta que requisitava a retomada futura de tais conceitos, o que foi realizado sem prejuízo da motivação discente. Relataram, também, perceber os alunos começando a tentar explicar fenômenos do cotidiano, como a visão, por exemplo, através dos conceitos de transdução, potencial de ação, comunicação sináptica e circuitos neuronais, que, colocando-se em ação, buscam "interpretar" ou "executar" um determinado comportamento. Cientes da existência de alguns alunos que aprendem mais que outros, aqueles eram incentivados a ajudar estes no esclarecimento de dúvidas de 
Santos, Barbieri e Sanchez / Alfabetização científica e iniciação científica: da assimilação de conceitos ao comportamento científico

entendimento sobre os fenômenos mais complexos. Cabe uma relevante observação dos coordenadores, que entendem terem superestimado o número de temas que poderiam ser abordados: o intenso interesse dos alunos não permitindo superficialidade na abordagem dos mesmos.

No "Caso 2: aspectos macroscópicos e microscópicos das doenças hepáticas", os orientadores verificaram, ao final do primeiro encontro, que os alunos possuíam conhecimento básico sobre o tema, mas, em termos específicos, ainda que já tivessem contato com microscópios, apresentavam muitas dificuldades para fazerem associações práticas. Os alunos tiveram interesse em saber como a vesícula biliar funcionava e como era constituído o sistema digestivo. Se pancreatite era causada por uso do álcool, se diabetes está relacionada ao fígado e por que a célula de Kupfer tinha nome diferente dos outros macrófagos do corpo. Os orientadores solicitaram aos alunos que sempre buscassem revisar, em casa, os conteúdos trabalhados. Houve interesse dos alunos em saber, também, qual o nome da principal célula do fígado, bem como por que o fígado de um morto é acinzentado e duro. Há registros de os alunos estarem fazendo anotações e desenhos para assimilar o conteúdo. Na sequência dos encontros, novas indagações discentes surgiram: se o vírus da hepatite atinge todas as células; por que o vírus $\mathrm{C}$ direciona-se para o fígado; o que leva à vermelhidão quando ocorre uma inflamação; como a célula identifica que está sofrendo um ataque, bem como se tanto o fígado saudável quanto o fígado doente tinham os "buracos" que eles estavam identificando. Os orientadores registraram, também, a ocorrência de questionamentos no WhatsApp. A partir do quinto encontro, os orientadores verificaram que os alunos começavam a apresentar vocabulário científico, ainda que dificuldades no uso da escrita da língua portuguesa fossem identificadas. Há registro de apropriação de conceitos pelos alunos quando estes, ao nomearam seu grupo de trabalho "Doenças Hepáticas", substituíram "do fígado" por "hepático", ainda que certa insegurança por parte deles na apresentação dos temas tenha sido percebida. Nos encontros seguintes, diferenças na assimilação de conteúdos evidenciou a necessidade de revisões conceituais, resultando na compreensão dos alunos de que as doenças estudadas podiam ser sequência uma das outras. Há registro de os alunos terem percebido que existem alterações no fígado que se estendem a outros órgãos como o baço e o cérebro, bem como de eles já saberem explicar o motivo de o fígado chegar a um processo de cirrose mesmo sendo um órgão que se regenera. Por ocasião de se discutir o que era o método científico, há registro de os alunos terem manifestado dificuldade em sintetizar o volume de conteúdo aprendido. Finalizando os encontros, os orientadores registraram a superação das dificuldades com o volume do conteúdo.

Em Menga Lüdke (2001, p. 30), tem-se que a literatura específica e a legislação sobre formação de professores já admitem a importância da pesquisa na preparação e no trabalho do professor. Essa perspectiva, entretanto, nem sempre foi realidade. Em trabalho anterior, sobre a socialização profissional de professores, essa autora (LUDKE, 2001, p. 27-28) afirma sua surpresa ao, entrevistando professores sobre a prática da pesquisa e a presença desta em sua formação, constatar que esta sequer foi mencionada pelos entrevistados. Ao que Contreras (1997) prontamente se posiciona, afirmando que é 
Santos, Barbieri e Sanchez / Alfabetização científica e iniciação científica: da assimilação de conceitos ao comportamento científico

de uma boa formação teórica, acompanhada de pesquisa e reflexão crítica, que o professor conseguirá embasamento para compreender melhor os problemas e as características da escola, ultrapassando perspectivas limitadoras de seu trabalho docente.

Contextualizando tal perspectiva aos resultados do programa Pequeno Cientista, o que se verifica é que, valorizando as manifestações de docentes e discentes ao longo das dez semanas de cada projeto, o programa acena como oportunidade de valorizar como ocorre a aprendizagem, o que tal processo provoca no pesquisador, a saber, a busca por uma explicação do que ele está orientando, e a valorização da escola muito mais pelos professores que ela tem do que pelos livros e apostilas que disponibiliza. Por adição, o professor que acompanha os alunos que participam do programa, abre, na escola, espaço para que os alunos apresentem para outros alunos os trabalhos que desenvolveram no programa, oportunizando participação igual a todos.

Entretanto, segundo André (2001, p. 63), não sendo incomum ouvir de professores, diretores, coordenadores e demais profissionais ligados à educação escolar que, muitas vezes, pesquisas não oferecem resposta prática a problemas das escolas, geralmente pontuais, haveria a possibilidade real de tal replicação de alcance nas escolas? Huberman (1999) entende que sim, através da interação e trabalho conjunto que o trabalho com pesquisa viabiliza. Isso nos leva de volta ao programa Pequeno Cientista, ao verificarmos que muito de seus orientadores, em sua maioria pós-graduandos, demonstraram falta de prática em explicitação de projetos. Com isso, revelam dificuldade em colocar suas decisões em formato de propostas a serem testadas, principalmente aquelas relativas ao desempenho dos alunos orientados, que seriam, em suma, hipóteses de aprendizagem a serem avaliadas. Vianna (1982, p. 26-27) e Da Silva (2009), acerca da avaliação do desempenho escolar, a pontuam como fundamental para uma educação eficiente. Retomando Bloom (1956), que, em linhas gerais, entende "conhecimento" como o conteúdo retido pelo aluno, enfatizador dos processos psicológicos do ato de lembrar, que está presente no Programa, na recordação de noções específicas e gerais, bem como em suas analogias, por ocasião da alfabetização científica dos alunos.

Entendemos, então, que a partir da assimilação dos conceitos pela alfabetização científica - momento dos dez encontros - inicia-se o processo de aquisição de um comportamento científico, composto pelas habilidades desenvolvidas anteriormente, focado na aplicação destes conceitos, na elaboração do pré-mural e mural. Iniciar cientificamente um aluno, portanto, sendo por nós entendido como, de posse do conhecimento de conceitos básicos de um determinado tema, promovido pela alfabetização científica, viabilizar que este aluno exercite o passo a passo do método científico em uma determinada investigação de sua escolha, direcionando o aluno ao aprendizado de maneira construtiva. Em Heck et al. (2012) temos que, em programa similar ao exposto neste trabalho, respeitadas as diferenças etárias e de etapas, o método científico foi introduzido no currículo de alunos para que alcançassem um melhor rendimento quando fossem para a universidade. Em que tais pesquisadores se basearam para tal? De acordo com Heck et al. (2012, p. 449), no fato de que o uso do método científico, para resolver problemas contextuais da vida quotidiana, permite $o$ desenvolvimento de procedimentos neurais universais para a resolução de inúmeros 
Santos, Barbieri e Sanchez / Alfabetização científica e iniciação científica: da assimilação de conceitos ao comportamento científico

outros tipos de problemas. Isso se deve, em parte, ao impacto emocional que essas rotinas neurais impõem ao cérebro humano. Assim, baseados nos resultados que temos obtido ao longo desses anos, acreditamos que o Programa da Casa consiga desenvolver estímulos que, ligados ao sistema de recompensa do cérebro, transformem o aprendizado em prazer, promovendo uma educação de alta qualidade.

\section{CONSIDERAÇÕES FINAIS}

Tomando por base os resultados mencionados, acreditamos que seja na alfabetização científica que ocorra tanto uma inter-relação do conteúdo de ciências a outras informações que as crianças leem em seu cotidiano quanto uma organização de ideias nos materiais por elas desenvolvidos. Acrescente-se a isso que tal atividade, no ensino básico (fundamental e médio), também assoma como fértil complemento curricular, enquanto atividade extraclasse, em parâmetro transversal e como suporte de conteúdo ao professor desprovido de formação em pesquisa e à escola sem infraestrutura adequada para tal.

Dentre as diretrizes que norteiam a Capes, promover o envolvimento de pósgraduandos na transferência de conhecimento para a sociedade, elevando o desenvolvimento nacional, regional e local da educação básica, é uma realidade. A experiência dos pesquisadores-orientadores e de alunos dos ensinos fundamental e médio, aqui relatadas, reafirma a importância de programas similares no processo de escolha profissional de jovens, os quais incentivem esses jovens a seguirem carreiras científicas, contribuindo para a projeção do futuro do país. Por conseguinte, a manifestação do comportamento científico dos alunos é evidenciada quando os alunos são entrevistados pelos orientadores no início das reuniões, bem como na confecção do pré-mural e apresentação do mural. Momento de desafio dos alunos, estes se revelam através do exercício do comportamento científico. Em conjunto, reafirma que a articulação de pósgraduandos com alunos da educação básica reforça a construção de conhecimento qualitativo de ambos em ambientes acadêmicos e de pesquisa, comprometendo a pósgraduação stricto sensu com as necessidades sociais da educação.

\section{Referências}

ALMEIDA, G. M. B. A peculiaridade do signo linguístico num vocabulário técnicocientífico especializado. In: ENCONTRO NACIONAL SOBRE LÍNGUA FALADA E ENSINO, 1., 1995, Maceió. Anais... : Universidade Federal de Alagoas, 1995.

ANDRÉ, M. Pesquisa, formação e prática docente. In: ANDRÉ, M. (Org.). O papel da pesquisa na formação e na prática dos professores. Campinas: Papirus, 2001 . p. 5569.

ARRUDA, A. Teoria das representações sociais e teorias de gênero. Cadernos de Pesquisa, São Paulo, n. 117, p. 127-149, 2002. 
Santos, Barbieri e Sanchez / Alfabetização científica e iniciação científica: da assimilação de conceitos ao comportamento científico

BLOOM, B. S. et al. Taxonomy of educational objectives. New York: David Mc-Kay, 1956. (Handbook I: Cognitive Domain).

BRASIL. Lei $\mathrm{n}^{\circ} 11.502$, de 11 de julho de 2007. Modifica as competências e a estrutura organizacional da fundação Coordenação de Aperfeiçoamento de Pessoal de Nível Superior - Capes... Diário Oficial da União, Brasília, DF, 12 jul. 2007.

Decreto $\mathrm{n}^{\mathrm{o}}$ 6.755, de 29 de janeiro de 2009. Institui a Política Nacional de Formação de Profissionais do Magistério da Educação Básica, disciplina a atuação da Coordenação de Aperfeiçoamento de Pessoal de Nível Superior - CAPES no fomento a programas de formação inicial e continuada, e dá outras providências. Diário Oficial da União, 30 jan. 2009.

CABRÉ, M. T. Theories of terminology: their description, prescription and explanation. Terminology, Amsterdam, v. 9, n. 2, p. 163-200, 2003.

CHASSOT, A. Scientific literacy: a possibility for social inclusion. Revista Brasileira de Educação, Rio de Janeiro, n. 22, p. 89-100, 2003.

CONSELHO NACIONAL DE DESENVOLVIMENTO CIENTÍFICO E TECNOLÓGICO. Chamada INCT - MCTI/ CNPq/Capes/FAPs nº 16/2014. Brasília, DF, 2014.

CONTRERAS, J. D. La autonomía del profesorado. Madrid: Morata, 1997.

DA SILVA, J. A. A fraude educacional brasileira. Ribeirão Preto: Funpec, 2009.

DA SILVA, J. A. Inteligência Humana: abordagens psicológicas e cognitivas. São Paulo: Lovise, 2003.

DE MEIS, L. Ciência e educação - O conflito humano-tecnológico. Rio de Janeiro: Ed. do Autor. 1998.

DEBOER. G. E. Scientific literacy: another look at its historical and contemporary meanings and its relationship to science education reform. Journal of Research in Science Teaching, Hoboken, v. 37, n. 6, p. 582-601, 2000.

DYER, H. S. Educational measurement - its nature and its problems. In: BERG, H. D. (Ed.). Evaluation in social studies. Thirty-fifth Yearbook of the National Council for the Social Studies. Washington, DC: National Education Association, 1965.

ECO, U. Como se faz uma tese. São Paulo: Perspectiva, 1998.

FERREIRO, E. Psicogênese da língua escrita. Porto Alegre: Artmed, 1985. 
Santos, Barbieri e Sanchez / Alfabetização científica e iniciação científica: da assimilação de conceitos ao comportamento científico

HECK, T. G. et al. Iniciação científica no ensino médio: um modelo de aproximação da escola com a universidade por meio do método científico. RBPG, Brasília, DF, n. 2, v. 8, p. 447 - 465, 2012.

HOUAISS, A.; VILLAR, M. S. Dicionário Houaiss da língua portuguesa. Rio de Janeiro: Objetiva, 2001.

HUBERMAN, M. The mind is its own place: the influence of sustained interactivity with practitioners on educational research. Harvard Educational Review, Cambridge, v.39, n. 3, p.289-318, 1999.

HURD, P. D. Scientific literacy: new minds for a changing world. Science Education, Hoboken, v. 82, n. 3, p. 407-416, 1998.

KATO, M. A. Alfabetização. In: Anais do Seminário Aprendizagem da Língua Materna: uma abordagem interdisciplinar. Brasília: Inep, 1984. p. 59-61.

KERLINGER, F. N. Foundations of Behavioral Research. New York: Holt, 1973.

KRAMER, S. Privação cultural e educação compensatória: uma análise crítica. Cadernos de pesquisa, São Paulo n. 42, p. 54-62, 1982.

LABOV, W. Padrões sociolinguísticos. São Paulo: Parábola, 2008.

LEMLE, M. A tarefa da alfabetização: etapas e problemas no português. Letras de Hoje, Porto Alegre, v.17, n. 4, p. 41-60, 1984.

LÜDKE, M. A complexa relação entre o professor e a pesquisa. In: ANDRÉ, M. (Org.). $O$ papel da pesquisa na formação e na prática dos professores. Campinas: Papirus, 2001. p. 27-54.

MACIEL, A. M. B. Linguagens especializadas e terminologia. In: PERNA, C. L. (Org.). Linguagens especializadas em corpora: modos de dizer e interfaces de pesquisa [recurso eletrônico]. Porto Alegre: EdiPUCRS, 2010.

MALUF, M. R. Alfabetização na pré-escola: conceitos e pré-conceitos. Teoria e Pesquisa, São Carlos, v. IX, n 26, p. 132-14, 1987.

MARCUSCHI, L. A. Da fala para a escrita: atividades de retextualização. São Paulo: Cortez, 2007.

MARTINS, I. Alfabetização científica: metáfora e perspectiva para o ensino de ciências. In: ENCONTRO DE PESQUISA EM ENSINO DE FÍSICA, 11, 2008, Curitiba. Anais... Curitiba: Universidade Tecnológica Federal do Paraná, 2008. Disponível em: < https://goo.gl/oR4jAc>. Acesso em: 30 maio 2017. 
Santos, Barbieri e Sanchez / Alfabetização científica e iniciação científica: da assimilação de conceitos ao comportamento científico

MILlER, J. D. Scientific literacy: a conceptual and empirical review. Daedalus, Cambridge, v. 112, n. 2, p. 29-48, 1983.

MINAYO, M. C. S. (Org.). Pesquisa social: teoria, método e criatividade. Petrópolis: Vozes, 2001.

PIAGET, J. A equilibração das estruturas cognitivas. Rio de Janeiro: Zahar, 1975a.

Como se desarolla la mente del niño. In: PIAGET, J. et al. Los años postergados: la primera infancia. Paris: Unicef, 1975b.

Biologia e conhecimento. 2. ed. Petrópolis: Vozes, 1996.

Seis estudos de psicologia. Rio de Janeiro: Forense Universitária, 1999.

PIAGET, J.; INHELDER, B. A psicologia da criança. São Paulo: Difel, 1982.

RATCLIFFE, M.; GRACE, M. Science education for citizenship: teaching socioscientific issues. Maidenhead: Open University Press, 2003.

ROCKEFELLER BROTHERS FUND. The pursuit of excellence: Education and the future of America. In: Prospect for America: report number $\mathrm{V}$ of the Rockefeller Panel Reports. Garden City, NY: Doubleday, 1958.

SHEN, B. S. P. Science literacy. American Scientist, New Haven, v. 63, n. 3, p. 265268, 1975.

Science literacy and the public understanding of science. In: DAY, S. B. Communication of Scientific Information. Basel: S. Karger, 1975. p. 44-52.

SILVA, M. B. Leitura, ortografia e fonologia. São Paulo: Ática, 1981.

SOARES, M. B. As muitas faces da alfabetização. Cadernos de Pesquisa, São Paulo, n. 52, p. 19-24, 1985.

VIANNA, H. M. Testes em educação. São Paulo: Ibrasa, 1982.

Recebido em 07/08/2017

Aprovado em 06/12/2017 